\title{
AVALIAÇÃO DO DESEMPENHO CLÍNICO DE RESINAS COMPOSTAS COM PRAZOS DE VALIDADE VENCIDOS
}

Ana Paula Pasqualin TOKUNAGA; Renata Seleme POSSEBON; Suzana dos SANTOS; Paulo Cesar Gonçalves dos SANTOS

Tendo em vista que muitos cirurgiões-dentistas, inadvertidamente ou de forma proposital, no segundo caso visando à redução de gastos, fazem uso de resinas compostas com prazos de validade vencidos, elaborou-se esta análise com o objetivo de observar o desempenho clínico do material em questão. Esta pesquisa tem por objetivo avaliar a polimerização das resinas compostas com prazo de validade extrapolado utilizando-se o corante Astra Blue, que tem por finalidade destacar a resina não-polimerizada, uma vez que possui afinidade pelos radicais livres encontrados nessas moléculas. As resinas vencidas, de marcas comerciais conhecidas, foram acondicionadas em orifícios circulares presentes em placas de diferentes espessuras, milimetradas de forma padronizada; as mesmas resinas foram então polimerizadas com um aparelho fotopolimerizador calibrado para uma exposição de 40 segundos, de forma a padronizar os resultados, anotando-se, então, as discrepâncias observadas. Este trabalho espera orientar os profissionais quanto à possibilidade real ou não de resinas compostas vencidas serem utilizadas na prática clínica, além de estabelecer a partir de quanto tempo depois de vencidas elas perdem sua capacidade de polimerização. 